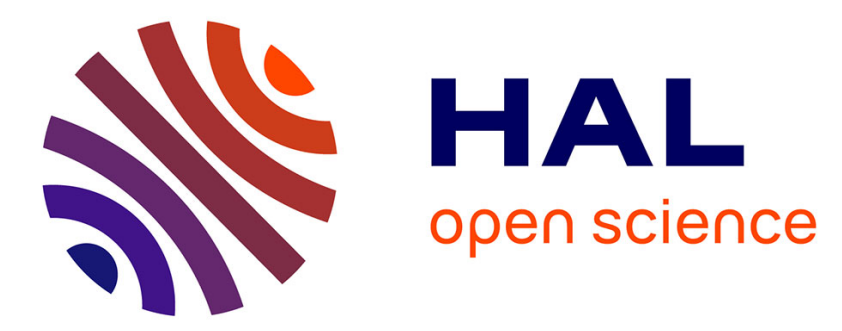

\title{
Application of Positron Annihilation in the Si Integrated Circuit (IC) Industry
}

\author{
Alec Reader, H. Schut, R. Hakvoort, A. van Veen
}

\section{To cite this version:}

Alec Reader, H. Schut, R. Hakvoort, A. van Veen. Application of Positron Annihilation in the Si Integrated Circuit (IC) Industry. Journal de Physique IV Proceedings, 1995, 05 (C1), pp.C1-27-C136. 10.1051/jp4:1995103 . jpa-00253539

\section{HAL Id: jpa-00253539 https://hal.science/jpa-00253539}

Submitted on 1 Jan 1995

HAL is a multi-disciplinary open access archive for the deposit and dissemination of scientific research documents, whether they are published or not. The documents may come from teaching and research institutions in France or abroad, or from public or private research centers.
L'archive ouverte pluridisciplinaire HAL, est destinée au dépôt et à la diffusion de documents scientifiques de niveau recherche, publiés ou non, émanant des établissements d'enseignement et de recherche français ou étrangers, des laboratoires publics ou privés. 


\title{
Application of Positron Annihilation in the Si Integrated Circuit (IC) Industry
}

\author{
Alec H. Reader*,(1), H. Schut**, R.A. Hakvoort** and A. van Veen** \\ * CNET: ST Microelectronics, Centre Commun, BP. 16, 38921 Crolles, France \\ ** Interfaculty Reactor Institute, Mekelweg 15, $2629 \mathrm{JB}$ Delft, The Netherlands
}

\begin{abstract}
Currently the trend in the Si IC industry is to produce epitaxial material layers by advanced growth and deposition techniques. Examples of these are $\mathrm{Si}$ and $\mathrm{SiGe}$ low temperature epitaxy, Si selective epitaxy and metallic silicide epitaxy. In order to obtain good electrical properties it is important that the epitaxial material shows no extended lattice defects and has a minimal concentration of lattice point defects. Given the concentrations of these phenomena a sensitive experimental technique is required to characterise the materials. The application of the positron annihilation technique in this IC research area is demonstrated by two examples, namely, characterization of $\mathrm{Si}$ Molecular Beam Epitaxy (MBE) and Atmospheric Pressure Chemical Vapour Deposition (APCVD) epi-layers and the assessment of the quality of $\mathrm{CoSi}_{2}$ epi-layers produced by the solid-state reaction with the $\mathrm{Si}$ substrate and an amorphous $\mathrm{CO}_{75} \mathrm{~W}_{25}$ sputtered layer. Results will be presented in terms of defect concentrations derived from positron diffusion lengths.
\end{abstract}

\section{INTRODUCTION}

Positron annihilation is beginning to play a role in the characterisation of a number of materials used in Si integrated circuits as can be understood, for example, from various topics covered in this conference. In this paper, examples will be given of two different research and development areas where a need for positron annihilation currently exists or will exist in the short term. These areas are, namely, the characterisation of a) epitaxial silicon layers on $\mathrm{Si}$ substrates (layer deposition by new/advanced techniques) and b) epitaxial metallic films on/in $\mathrm{Si}$ (for future metallisations and advanced transistors). In the following sections, these two subject areas will be discussed. Epitaxial Si layers will be addressed first.

Over the last few years a number of positron annihilation studies have been carried out on $\mathrm{Si}$ epitaxial layers on Si substrates [1,2,3]. Currently, the trend in the industry is to grow epitaxial Si (and SiGe) layers at low temperatures $\left(\sim 700^{\circ} \mathrm{C}\right.$ ). Great progress has recently been made in advanced deposition techniques which allows $\mathrm{Si}$ (and SiGe) epitaxial growth at a temperature well below those normally $\left(>1000^{\circ} \mathrm{C}\right.$ ) employed. The main driving force for this temperature decrease is reduced dopant diffusion in the Si substrate and in the epitaxial layer. For example, in modern bipolar (and BiCMOS) transistors, localised dopant regions are introduced into the Si substrate prior to epitaxy. During epitaxy, thin doped layers with very large dopant gradients may be incorporated into the growing material. It is extremely

(1) Currently on assignment from Philips Research Labs, 5600 JA Eindhoven, The Netherlands 
beneficial if dopant diffusion in the substrate and in the epitaxial material is minimal for high speed transistor operation. The simplest way to limited dopant diffusion is to reduce processing temperatures. Thus the origin of the current trend. Particularly for bipolar applications, it is important that the epitaxial material has a good crystalline quality: a good crystalline quality is defined here as a material containing no extended lattice defects (dislocations and stacking faults) and a minimal concentration of lattice point defects, i.e., substitutional vacancies and interstitials. Such point defects can act as strong trapping centres for minority carriers and as the operation of bipolar devices relies on these carriers, it can be understood that the performance of transistors is impaired by the presence of point defects. For MOS transistor applications, the effect of point defects on device performance is probably less critical.

Another aspect of Si epitaxy on Si substrates which is also currently under investigation is selective epitaxy. Si epitaxy was previously solely carried out over the whole wafer (i.e. as a blanket deposition) and before any process steps. The trend in research at the moment is selective epitaxial growth on exposed $\mathrm{Si}$ regions (i.e. no growth on patterned $\mathrm{SiO}_{2}$ areas) after certain process steps have been carried out, the main driving force here being the need for closely packed alternating $\mathrm{SiO}_{2} / \mathrm{Si}$ regions for "ultra large scale" (deep sub-micron) integrated circuits. The active MOS transistor is subsequently constructed in the $\mathrm{Si}$ regions while the $\mathrm{SiO}_{2}$ acts as an electrically isolating area between adjacent transistors. An example of the manufacture of such a structure is shown in figure 1. In this figure, it is shown that independent $\mathrm{n}$ - and $\mathrm{p}$-wells are formed by using selective-epitaxial doped material for $\mathrm{p}$ - and $\mathrm{n}$-channel CMOS devices. Here the use of ion-implantation and high temperature processing is not needed. Furthermore, retrograde-well [4] and bipolar structures can be relatively easily incorporated into wafer processing.

\section{Thermal or CVD Oxide}
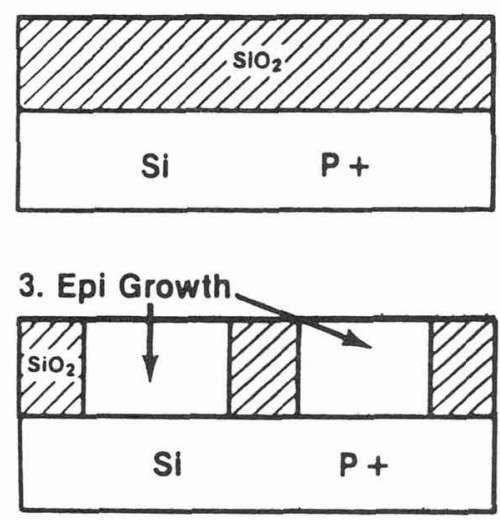

\section{Etch Windows}

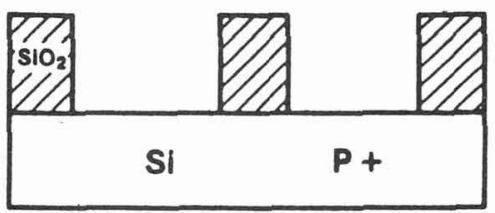

4. N.Well Drive-In

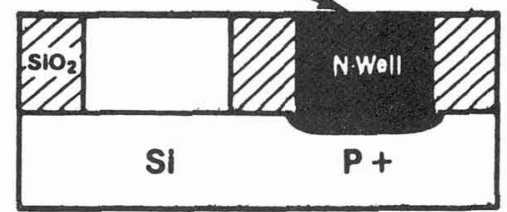

Figure 1. Basic selective epi-growth process for an n-well CMOS structure.

Returning to the subject of epitaxial quality, it is important to gain an understanding of the issues that are critical for the production of material with a minimal concentration of point defects. In general, lowering the epitaxial growth temperature normally leads to the incorporation of an increased number of point defects [5]. This occurs as the surface mobility 
of the ad-atoms is reduced at low temperature and thus an ad-atom may not be able to fill a vacancy before the subsequently deposited ad-atom arrives. This situation is schematically shown in figure 2 . Here, the ad-atom on the growing surface can not move far enough along the surface to fill the vacancy before the next deposited atom arrives. Obviously, if the time between subsequently deposited atoms is great, then there is a high probability the surface ad-atom can fill the vacancy. In other words, if the deposition rate is small, the vacancy concentration should also be low. Conversely, a large deposition rate at a comparable temperature should lead to a high vacancy concentration. Unfortunately, almost all analytical techniques cannot detect the presence of vacancies. As positron annihilation is sensitive to the presence of vacancies and vacancy-clusters, it has been used to study such growth phenomena. Using positron annihilation, the effect of growth rate on vacancy concentration will be demonstrated in this paper.

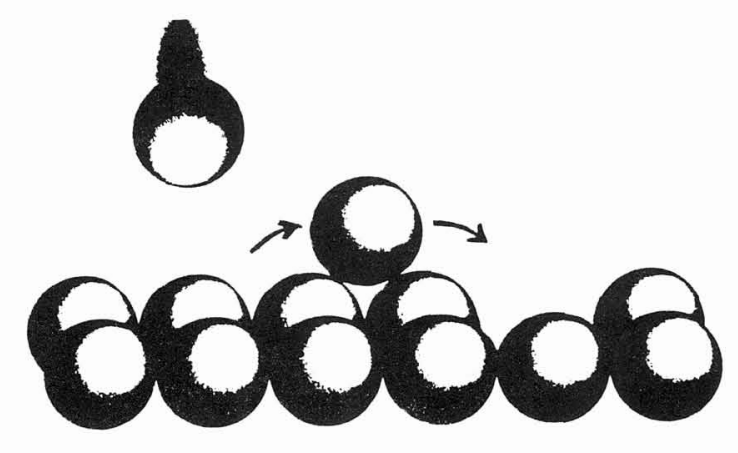

Figure 2. Schematic picture of an ad-atom diffusing on a growing surface during the deposition of a next ad-atom.

The study of epitaxial metallic silicides by positron annihilation is the second example of the technique's application in IC research and development. Interest in epitaxial silicides originates from their (potential) uses. There are basically two application areas: a) Schottky \& ohmic contacts to $\mathrm{Si}$ where epitaxial silicides have a better thermal stability than polycrystalline material and b) advanced transistors such as the Metal Base and Permeable Base Transistors where the metallic silicide is the controlling electrode in the device [6]. For both application areas, although there are a number of candidate materials, the metallic silicide $\mathrm{CoSi}_{2}$ (and to a lesser extent $\mathrm{NiSi}_{2}$ ) has received most attention. Here, good quality epitaxial material is desirable for superior electrical conduction properties. (Again, good epitaxial quality is defined as a low concentration of lattice point defects). An established method for producing the metallic silicides, $\mathrm{CoSi}_{2}$ and $\mathrm{NiSi}_{2}$, is metal ion implantation into the silicon substrate, followed by very high temperature $\left(\sim 1100{ }^{\circ} \mathrm{C}\right)$ annealing. Unfortunately, this normally results in a relatively thick buried $\mathrm{CoSi}_{2}$ layer which is not suitable for application in the areas mentioned 
above (for the first application area, a surface silicide is required). Furthermore, such ion implantation leads to the formation of a large amount of lattice damage which is difficult to remove and degrades the performance of devices. Also, as described above, the trend in the industry is to low processing temperatures to limit dopant diffusion and the like. Thus, a search was started for a low temperature epitaxial $\mathrm{CoSi}_{2}$ production method. Low temperature, non-implantation, methods for $\mathrm{CoSi}_{2}$ epitaxy have now been devised $[7,8,9]$ which rely on the use of layers deposited in a standard sputter machine and an anneal. However, the following question arises: is the epitaxial quality of the silicide formed by the new methods the same as the material produced by the implantation technique? Electrical measurements [10] suggested that there is a difference between the films, but no differences could be found by analytical techniques including transmission electron microscopy (TEM). In this paper, the epitaxial quality of silicide films produced by two methods will be compared with the aid of positron annihilation studies and the origin of the electrical difference elucidated.

\section{POSITRON ANNIHILATION TECHNIQUE}

The positron beam used in these studies consisted of a beam of about $5 \times 10^{4}$ monoenergetic positrons per second with energy $E$ adjustable from near $100 \mathrm{eV}$ to $30 \mathrm{keV}$ $[11,12]$. The stopping profile of the implanted positrons in a material is approximated by a derivative of a gaussian with the mean implantation depth being proportional to $E^{j .6}$. In $\mathrm{Si}$, for example, this range of energies corresponds to mean implantation depths ranging from near 0 to $3 \mu \mathrm{m}$. After being slowed down, positrons implanted in the bulk of the material start to diffuse and ultimately annihilate either in a defect free region or become trapped in a defect (especially an open-volume defect) and annihilate there. The Doppler shifted energy of the photons created in the two-photon annihilation process depends on the momentum of the electron-positron pair. Since in defects the electron momentum distribution is in general different from the one in a defect-free region, the energy distribution (around $511 \mathrm{keV}$ ) of the photons carries information about the presence of defects. It is common use to characterize the width of the Doppler broadened annihilation peak by the so-called " $S$-parameter". This parameter is defined as the area of a central region of the line divided by the total area of the line. In general the $S$-parameter of positrons annihilating in open-volume defects is higher than the one of the defect-free material, although in the case of oxygen related defects in Si a lower $S$-parameter is observed. For an overview of the positron beam techniques see [13].

Measurement of the $S$-parameter not only yields information about the type of defects but also about the depth distribution and concentration of the defects. The latter can be derived from the positron diffusion length which can be resolved from the $S$-parameter measured as a function of the positron implantation energy. For each positron implantation energy the $S$ parameter can be written as:

$$
S(E)=F_{s}(E) S_{s}+F_{b}(E) S_{b}+F_{t}(E) S_{t},
$$

were $F_{s}(E), F_{b}(E)$ and $F_{t}(E)$ denote the energy dependent fractions of positrons annihilating at the surface, in the bulk or at a defect with specific $S_{s}, S_{b}$ and $S_{t}$ values, respectively.

The different fractions can be calculated from the balance between positron implantation, diffusion, bulk annihilation and trapping by solving the time-averaged, one dimensional diffusion equation: 


$$
\text { D. } \frac{d^{2} c(z)}{d z^{2}}-\frac{d\left[v_{d} c(z)\right]}{d z}-\left[v_{t} n_{t}(z)+\lambda_{b}\right] c(z)+P(z, E)=0
$$

with $D_{+}$the positron diffusion coefficient, $c(z)$ the positron density as a function of depth, $v_{d}$ the field dependent drift velocity, $v_{t}$ the specific positron trapping rate in the defect under consideration, $n_{t}$ the defect density (in atomic fraction) and $\lambda_{b}$ the positron bulk annihilation rate. $P(z, E)$ is the energy dependent positron implantation profile. The relation between the defect concentration $n_{t}$ and the observed effective diffusion length $L_{+, e f f}$ is given by

$$
n_{t}=\frac{\lambda_{b}}{v_{t}}\left[\left(\frac{L_{+}}{L_{*}, e f f}\right)^{2}-1\right]
$$

with $L_{+}$the positron diffusion length in defect-free material. Equation (2) forms the basis of a modelling and fitting program VEPFIT [14] used to analyse the experimental data presented below.

\section{RESULTS}

\subsection{Epitaxial layers on $\mathrm{Si}$}

Positron beam measurements have been performed on Si-epitaxial layers deposited by molecular beam epitaxy (MBE) and atmospheric pressure chemical vapour deposition (APCVD) techniques. The $3 \mu \mathrm{m}$ thick MBE layer has been deposited on a p-type, $0.01 \Omega \mathrm{cm}$ boron doped Si substrate at a deposition temperature of $1013 \mathrm{~K}$ and at a deposition rate of 0.3 $\mathrm{nm} / \mathrm{s}$ (sample B). The APCVD depositions were carried out at a substrate temperature of 973 $\mathrm{K}$ and a deposition rate of $0.17 \mathrm{~nm} / \mathrm{s}$ (sample C) and at $873 \mathrm{~K}$ at $0.02 \mathrm{~nm} / \mathrm{s}$ (sample D), respectively. Sample A was a silicon substrate, i.e. grown from the melt phase, and acted as a reference sample. The results of the positron measurements together with the fitted curves produced by VEPFIT are shown in figure 3. Sample B (MBE) has been measured at room temperature and at a temperature of $400 \mathrm{~K}$. The most relevant fitted values for the relative Sparameters (defined as $\mathrm{S} / \mathrm{S}_{\mathrm{Si}}$ ) and the effective diffusion lengths are given in table 1 . This table also summarizes the deposition conditions and the derived defect concentrations. The diffusion length quoted for the MBE sample is obtained from the measurement at $400 \mathrm{~K}$ taking into account the $\mathrm{T}^{-0.5}$ relationship between the diffusion coefficient and temperature[15].

Table 1. Summary of the deposition conditions, fitted positron diffusion lengths and relative $S$-parameters for $S i$ samples $A$ to $D$. The vacancy concentration is derived from the diffusion

\begin{tabular}{|c|c|c|c|c|c|}
\hline $\begin{array}{l}\text { deposition } \\
\text { technique }\end{array}$ & $\begin{array}{l}\text { deposition } \\
\text { temperature } \\
\text { (K) }\end{array}$ & $\begin{array}{l}\text { deposition } \\
\text { rate } \\
(\mathrm{nm} / \mathrm{s}) \\
\end{array}$ & $\begin{array}{l}\mathrm{L}_{+, \text {eff }} \\
(\mathrm{nm}) \\
\end{array}$ & $\begin{array}{l}\text { vacancy } \\
\text { concentration } \\
\left(\mathrm{cm}^{-3}\right)\end{array}$ & $\begin{array}{l}\text { relative } \\
\mathrm{S} \text {-parameter } \\
\left(=\mathrm{S} / \mathrm{S}_{\mathrm{Si}}\right)\end{array}$ \\
\hline substrate $(\mathrm{A})$ & melt & -- & 245 & reference & 1 \\
\hline$M B E \quad$ (B) & 1013 & .3 & 220 & $2 \times 10^{17}$ & $1.01 \pm .01$ \\
\hline $\mathrm{APCVD}(\mathrm{C})$ & 973 & .17 & 133 & $2 \times 10^{18}$ & 1.044 \\
\hline $\mathrm{APCVD}(\mathrm{D})$ & 873 & .02 & 200 & $4 \times 10^{17}$ & 1.043 \\
\hline
\end{tabular}
lengths using equation (3) and $L_{+}=245 \mathrm{~nm}, \lambda_{b}=4.5 \times 10 \mathrm{~s}^{-1}$ and $v_{t}=3 \times 10^{14} \mathrm{~s}^{-1}$. [3] 

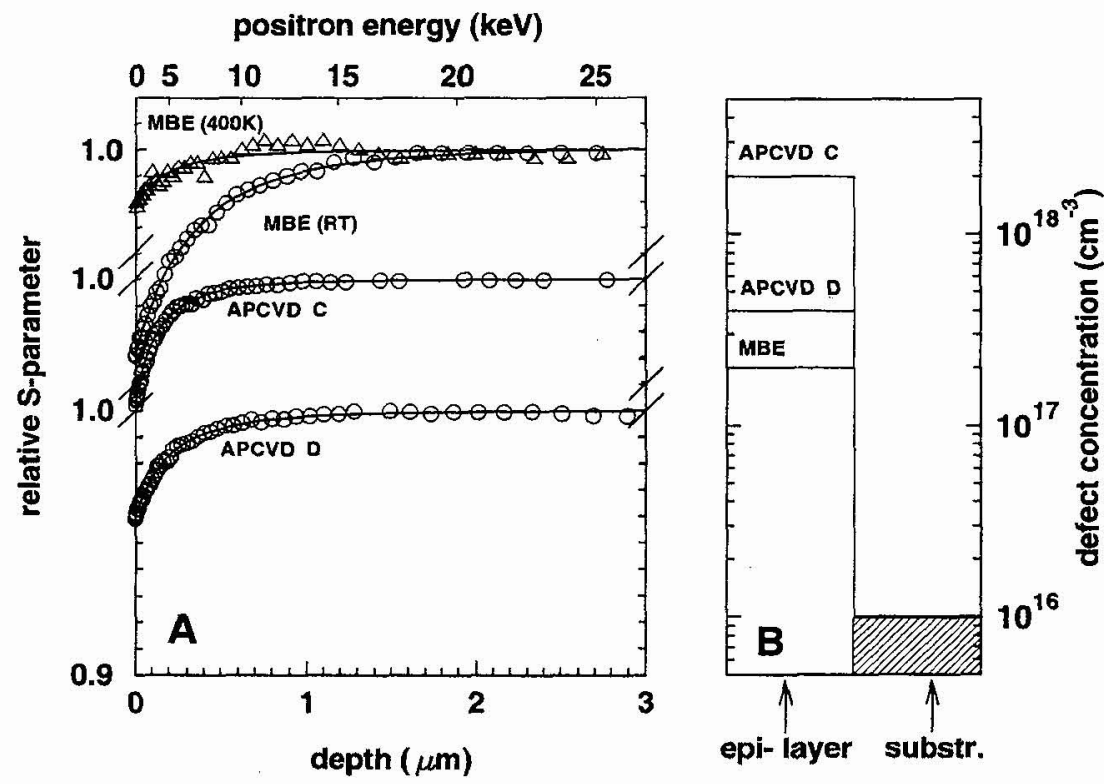

Figure 3. Panel A shows the measured relative $S$-parameters as a function of the mean positron implantation depth (bottom scale) or positron implantation energy (top scale). The data denoted MBE (400K) is measured at a sample temperature of $400 \mathrm{~K}$. All other measurements are performed at room temperature. The lines through the data are obtained using the fitting program VEPFIT. Panel B shows the fitted defect concentrations in the epilayers. The hatched area indicates that the defect concentration level in the substrate is below the detection limit for positrons.

\subsection{Metallic silicides: $\mathrm{CoSi}_{2}$}

The application of positron beams for the investigation of metallic silicides is demonstrated for the case of $\mathrm{CoSi}_{2}$ films produced by two different methods. One method employs the solidstate reaction between the silicon substrate and an amorphous $\mathrm{Co}_{75} \mathrm{~W}_{25}$ sputtered layer. The other method is based on the implantation of a very high dosis of Co into silicon. The implantation was carried out at an elevated temperature, in order to anneal damage created during the implantation.

The results of the positron beam experiments [16], shown in figure 4, were obtained from a $140 \mathrm{~nm}$ thick, magnetron sputtered $\mathrm{Co}_{75} \mathrm{~W}_{25}$ layer annealed at $825 \mathrm{~K}$ for 8 hours (sample $\mathrm{E}$ ) followed by an aneal at $1025 \mathrm{~K}$ for 1 hour (sample F). For comparison the result of a measurement on an implanted sample $(G)$ is also shown. This sample consisted of a $120 \mathrm{~nm}$ thick silicide layer prepared by Co implantation, followed by an anneal at $1275 \mathrm{~K}$ for 30 min and a subsequent anneal at $1075 \mathrm{~K}$ for 8 hours. A complete description of the growth conditions and substrate parameters can be found in [7]. The fit results for the three samples are summarized in table 2. 
Table 2. Fit results for the positron beam measurements of the CoSi $i_{2}$ samples $E, F$ and $G$. Defect concentrations are derived from the fitted positron diffusion lengths using eq.(3) with: $L_{+}=125 \mathrm{~nm}, \lambda_{b}=6.5 \times 10^{9} \mathrm{~s}^{-1}$ and $v_{t}=2.6 \times 10^{14} \mathrm{~s}^{-1}[17,18]$

\begin{tabular}{|c|c|c|c|}
\hline production method & $\begin{array}{l}\mathrm{L}_{+. \mathrm{eff}} \\
(\mathrm{nm}) \\
\end{array}$ & $\begin{array}{l}\text { defect concentration } \\
\left(\mathrm{cm}^{-3}\right)\end{array}$ & $\begin{array}{l}\text { relative S-parameter } \\
\qquad\left(=\mathrm{S} / \mathrm{S}_{\mathrm{Si}}\right)\end{array}$ \\
\hline $\mathrm{Co}_{75} \mathrm{~W}_{25}+825 \mathrm{~K}(\mathrm{E})$ & 32 & $2.6 \times 10^{19}$ & 1.0632 \\
\hline as $(E)+1025 \mathrm{~K} \quad(\mathrm{~F})$ & 96 & $1.1 \times 10^{18}$ & 1.0681 \\
\hline $\begin{array}{l}\text { Co implantation (G). } \\
+1275 \mathrm{~K}+1075 \mathrm{~K}\end{array}$ & 125 & reference & 0.9036 \\
\hline
\end{tabular}

\section{DISCUSSION}

Starting with the comparison of the Si epitaxial films, it can be understood that the deposition rate is an important parameter during film growth. Analysing Table 1, one can understand that changing the temperature of the substrate between 873 and $1013 \mathrm{~K}(600$ and $740{ }^{\circ} \mathrm{C}$ ) has a limited effect on the built-in vacancy concentration, whereas changing the deposition rate clearly causes a large variation in vacancy concentration. To highlight this point, one only has to compare depositions $\mathrm{B}$ and $\mathrm{D}$. Here the determined vacancy concentrations are about the same, while sample B was grown at temperature $140^{\circ} \mathrm{C}$ above $\mathrm{D}$. Yet the deposition rates differ greatly: the deposition rate of sample $\mathrm{B}$ was 15 times greater than D. Clearly more investigation is required to quantify this effect and to distinguish it from the influence of the deposition method employed. For example, in the comparison just described, two different deposition techniques were used. However, preliminary findings have indicated that vacancy concentration differences in layers, deposited at similar temperatures using the two techniques investigated in this study, are small compared to the deposition rate effects. The mechanism for building-in vacancies during growth has been described in the introduction. Clearly, the rate at which atoms arrive at the surface of a Si substrate is extremely important. If the surface ad-atoms do not have the time to diffuse to vacant sites on the surface before subsequent atoms arrive, vacancies will be left behind in the growing film. From the deposition rates in table 1 it can be calculated that the time $\tau_{\mathrm{m}}$ to grow a monolayer is $0.66 \mathrm{~s}$ for the MBE layer, $1.2 \mathrm{~s}$ for the APCVD(C) layer and $10 \mathrm{~s}$ for the APCVD(D) layer, respectively. Within this time atoms will spread in a zone around the place of deposition with a mean square radius of $\left\langle r^{2}\right\rangle=4 D \tau_{m}$, with $D_{s}$ the surface diffusitivity given by the expression $\mathrm{D}_{\mathrm{s}}=0.01 \mathrm{exp}\left[-\mathrm{E}_{\mathrm{sd}} / \mathrm{kT}\right]$. With the value for the activation energy for surface diffusion of $1 \mathrm{eV}$ $[19,20,21]$ the values of $\left\langle\mathrm{r}^{2}\right\rangle^{1 / 2}$ amount to $5 \times 10^{-3}, 5 \times 10^{-3}$ and $8 \times 10^{-3} \mathrm{~cm}$, respectively. Thus considerable distances can be covered before the next layer is deposited. It should be noted that though the APCVD(D) layer has been deposited at a $100 \mathrm{~K}$ lower temperature than the $\mathrm{APCVD}(\mathrm{C})$ layer, the range of diffusing surface atoms is twice that of the latter surface. Therefore more vancancy type defects might have been removed in that case. The positron results indicate a five times reduction.

The removal of defects by self diffusion of $\mathrm{Si}$ atoms is reduced considerably by going to lower temperatures. Based on an activation energy for Si self-diffusion of $4.8 \mathrm{eV}$ [22] the ratio of the diffusivity at 873 and 973 is of the order of $10^{-3}$. Since this is in disagreement with 


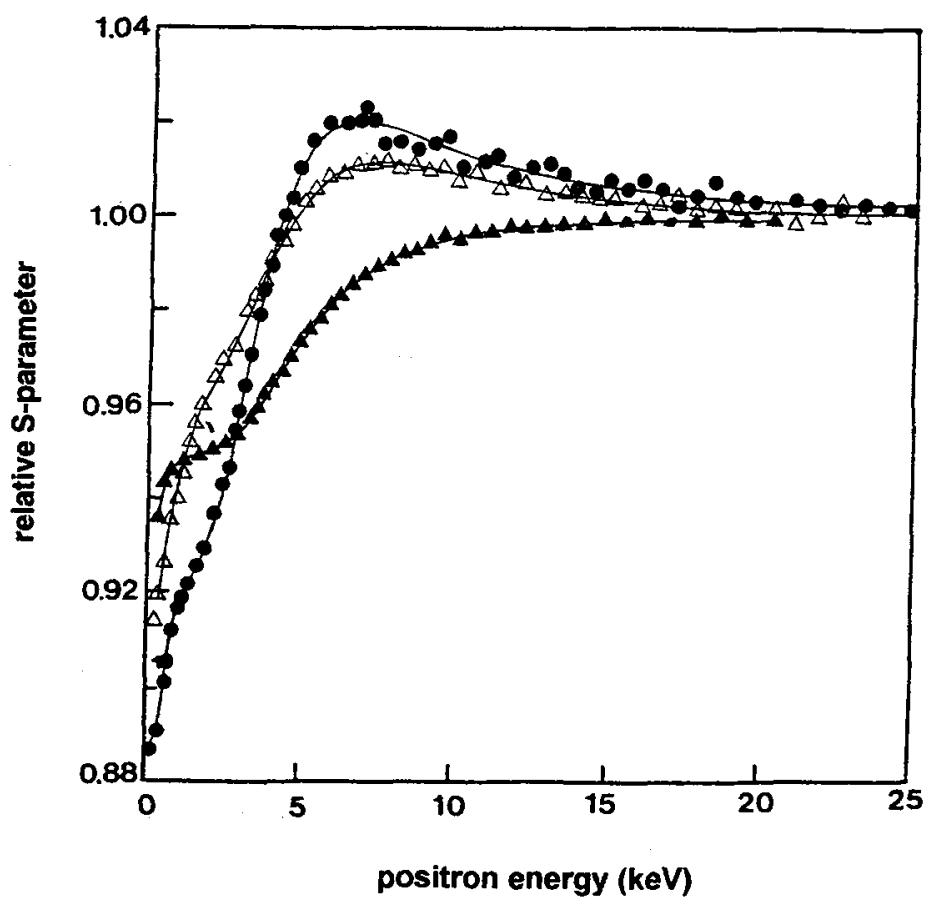

Figuire 4. Positron annihilation ineasurements on the three cobalt-disilicide samples.

-: $\mathrm{CoSi}_{2}$ formed at $825 \mathrm{~K}$ (sample $\mathrm{E}$ ), $\Delta: \mathrm{CoSi}_{2}$ annealed at $1025 \mathrm{~K}$ (sample $\mathrm{F}$ ), and

$\Delta$ : implanted $\mathrm{CoSi}_{2}$ (sample $G$ ). The $S$-values are relative to the $S$-values of crystalline $S i$.

the results derived from the positron measurements we believe that the observed reduction in defect concentration is due to the range of moving surface atoms and thus the deposition rate.

Turning our attention now to the subject of the epitaxial $\mathrm{CoSi}_{2}$ films, it is immediately apparent that the relative $S$ values for both films formed from sputtered layers by low temperature annealing (samples $\mathrm{E}$ and $\mathrm{F}$ ) are more than $17 \%$ higher than the value for the implanted silicide film produced by high temperature annealing. This relative shift in $\mathrm{S}$ can be explained in only one way: the materials formed from sputtered layers contain a certain concentration of rather large vacancy-type defects. This can be concluded because positron annihilation is one of the most sensitive techniques for the detection of the vacancy-type defects. Furthermore, it can also be concluded that the additional anneal between samples $\mathrm{E}$ and $F$ does not change the dominant type of defect, as the relative $S$ value does not significantly change. If one assumes that only one dominant type of defect is present, values for the positron diffusion lengths can be deduced. From the values of diffusion lengths, estimates for the defect concentrations in the films can be obtained. Using this technique, it can be shown (see table 2) that the concentration of defects decreases during the additional anneal between samples $\mathrm{E}$ and $\mathrm{F}$. The data obtained above is in very good agreement with 
electrical measurements. From very low temperature resistivity measurements on these films [10], it was indirectly concluded that these films contained a relatively high concentration of lattice defects. Film E apparently contained more defects than film F. However, these electrical measurements could not categorically identify these defects as vacancies. Furthermore, these measurements only gave an indication of the concentration of the defects. Positron annihilation, on the other hand, identified the type of defect and the concentration of the defects in the two films.

Returning briefly to the electrical measurements, by studying the change in resistivity of the films during heating to room temperature, the Debye temperatures for the two silicides could be obtained and compared with literature values. The determined values of Debye temperature suggested that the material after the first anneal (sample E) had a "less rigid" lattice than the film subjected to the additional anneal (sample F). This latter film was also in turn less rigid than good quality material reported in the literature. These results are again in agreement with the positron annihilation measurements which indicated that both samples $\mathrm{E}$ and $\mathrm{F}$ contain a high density of vacancies that leads to a less rigid lattice. Further, the positron results also determined that after the additional anneal (sample $F$ ), the number of vacancies decreases considerably, improving the rigidity of the $\mathrm{CoSi}_{2}$ lattice and thus the Debye temperature of the material.

\section{CONCLUSIONS}

It has been shown that positron beam analysis is an effective, non destructive tool to study the presence of vacancy-type defects in materials used in the Si IC industry. This has been demonstrated in a study on MBE and APCVD Si-epitaxial layers, in which the measured defect concentrations have been ascribed to the rate at which atoms arrive at the surface of the growing epitaxial layer. Differences in defect concentrations in the range between $2 \times 10^{17}$ and $2 \times 10^{18} \mathrm{~cm}^{-3}$ could easily be detected. The positron measurements on the $\mathrm{CoSi}_{2}$ samples reveal the presence of defects with concentrations as high as $2-3 \times 10^{19} \mathrm{~cm}^{-3}$. This rather high number decreases upon annealing at $1025 \mathrm{~K}$ by one order of magnitude. This result is in agreement with the observed decrease of the residual resistivity.

\section{REFERENCES}

[1] Schut H., van Veen A., van der Walle G.F.A. and van Gorkum A.A., J. Appl. Phys. 70 (1991) 3003.

[2] Gossmann H.J., Asoka-Kumar P., Leung T.C., Nielsen B., Lynn K.G., Unterwald F.C., and Feldman L.C. , Appl. Phys. Lett. 61 (1992) 540.

[3] Schultz P.J., Tandberg E., Lynn K.G., Nielsen B., Jackman T.E., Denhoff M., and Aers G.C., Phys. Rev. Lett. 61 (1988) 187.

[4] Borland J.O., "Low Temperature Silicon Epitaxy for Novel Device Structures", Reduced Thermal Processing for ULSI, NATO ASI Series B: Physics vol. 07, (Plenum, New York, 1989).

[5] van Veen A., Reader A.H., Gravesteijn D.J. and van Gorkum A.A., Thin Solid Films 241 (1993) 206.

[6] Reader A.H. et al, "Transition Metal Silicides in Silicon Technology: a review", Reports on Progress in Physics 56 (November 1992) 1397-1468.

[7] La Via F., Spinella C., Reader A.H., Duchateau J.P.W.B., Hakvoort R.A. and van Veen A., J. Vac. Sci. Technol. B 11(5) (1993) 1807.

[8] Dass M.L.A., Fraser D.B. and Wei C.S., Appl. Phys. Lett. 58 (1991) 1308. 
[9] Semiconductor International, (December 1993) 49.

[10] La Via F., Spinella C., Reader A.H., Duchateau J.P.W.B.,. Hakvoort R.A, and van Veen A., Appl. Surface Sci. 73 (1993) 108.

[11] Schut H., A Variable Energy Positron Beam Facility with Applications in Materials Science, thesis, Delft University of Technology, Delft, 1990.

[12] van Veen A., in: J. of Trace and Microprobe Techniques, 8, (Dekker, New York, Basel, 1990) pp. 1-29.

[13] Schultz P.J. and. Lynn K.G, Rev. Mod. Phys. 60 (1988) 701.

[14] van Veen A., Schut H., de Vries J., Hakvoort R.A., and IJpma M.R., "Analysis of positron depth profiling data by means of VEPFIT", Positron Beams for Solids and Surfaces, AIP Conf. Proc. 218, London, Ontario, Canada 3-6 July 1990 (AIP, New York, 1990) pp.171-196.

[15] Huomo H., Vehanen A., Bentzon M.D., and Hautojärvi P., Phys. Rev. B 35 (1987) 8252.

[16] Hakvoort R.A., Applications of Positron Depth Profiling, thesis, Delft University of Technology, Delft, 1993

[17] Garreau Y, Lerch P., Jarlborg T., Walker E., Genoud P., Manuel A.A. and Peter M. Phys. Rev. B 43 (1991) 14532.

[18] Nieminen R.M. and Manninen M.J., in: Positrons in Solids (Springer-Verlag, Berlin, 1979) pp. 145-195.

[19] de Jong T., Silicon Molecular Beam Epitaxy, thesis, Univ. of Amsterdam, 1983

[20] Henderson R.C. and Helm R.F., Surf. Sci. 30 (1992) 310.

[21] Kasper E., Appl. Phys. A 28 (1982) 129.

[22] Stolwijk N.A., Schuster B., Hölzl J., Mehrer H. and Frank W., Physica, 116B (1983) 335 . 